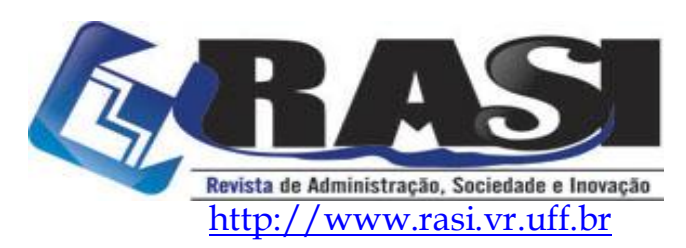

RASI, Volta Redonda/RJ, v. 7, n. 1, pp. 84-103, Jan./Abr. 2021

\title{
The End of Cheap China? Uma Análise do Catching up Produtivo e da Sofisticação das Exportações Chinesas entre 2001 e 2017.
}

\author{
Caroline Miranda Brandão (UNICAMP) - carolembm@gmail.com \\ Caroline Giusti Araújo (UNICAMP) - carolgiustiaraujo@gmail.com \\ Guilherme Nascimento Gomes (UNICAMP) - guingomes@gmail.com \\ Antonio Carlos Diegues (UNICAMP) - acdieguesjr@ gmail.com
}

\begin{abstract}
Resumo:
Este trabalho tem como objetivo avaliar como as mudanças na estrutura produtiva chinesa impactaram os preços de bens industriais exportados pelo país entre 2001 e 2017. Para isto, considera-se o preço sendo uma variável explicativa da qualidade das exportações. Metodologicamente propõe-se calcular as margens intensiva e de qualidade de acordo com Hummels e Klenow (2005) para grupos setoriais categorizados por tipos de tecnologia (intensivas em escala, diferenciadas e baseadas em ciência). Com isso, a análise dos setores intensivos em escala, diferenciados e baseados em ciência sinaliza que há um processo virtuoso de transformação produtiva e tecnológica chinesa à medida que se observa um aumento generalizado da relevância das exportações chinesas em terceiros mercados, via margem intensiva. No entanto, a margem de qualidade das exportações, representada pelo índice de preços, encontra-se em uma posição inferior comparativamente às principais economias em termos de desenvolvimento produtivo e tecnológico.
\end{abstract}

Palavras-Chaves: China; Comércio Internacional; Margens de Comércio; Índice de Preços; Estrutura Produtiva.

\section{The End of Cheap China? An Analysis of the Productive Catching up and the Sophistication of Chinese Exports between 2001 and 2017}

\begin{abstract}
:
This paper aims to evaluate how the changes in the Chinese productive structure impacted the prices of industrial goods exported by the country between 2001 and 2017, considering, for this, price an explanatory variable of the quality of exports. Methodologically, it is proposed to calculate the intensive and quality margins according to Hummels and Klenow (2005) for sector groups categorized by types of technology (intensive in scale, differentiated and based on science). As a result, the analysis of scale-intensive, differentiated and science-based sectors signals that there is a virtuous process of Chinese technological and productive transformation as there is a general increase in the importance of Chinese exports in third markets, via an intensive margin. However, the export quality index, represented by the price index, is in a lower position compared to the main economies in terms of productive and technological development.
\end{abstract}

Keywords: China; International Trade; Trade Margins; Price Index; Productive Structure.

\begin{tabular}{c}
\hline Rniversidade \\
R. Desembargador Ellis Hermydio Figueira, 783, Bloco A, sl. 218, Aterrado. \\
$27213-415$ - Volta Redonda, RJ - Brasil \\
www.uff.br \\
Copyright (C) 2020 RASI. Todos os direitos, até mesmo de tradução, são reservados. É \\
permitido citar parte de artigos sem autorização prévia, desde que seja identificada a fonte. \\
\hline
\end{tabular}




\section{The End of Cheap China? Uma Análise do Catching up Produtivo e da Sofisticação das Exportações Chinesas entre 2001 e 2017}

\section{Introdução}

A economia chinesa tem reestruturado sua inserção internacional desde o último quarto do século XX por meio da subordinação da política macroeconômica a uma estratégia de desenvolvimento baseada na transformação estrutural e na busca de longo prazo pela autonomia produtiva e tecnológica. Baseado nesta estratégia, o país se tornou um grande receptor de investimentos externos, com elevada participação no comércio internacional e saldo positivo na balança comercial em tecnologias mais nobres ${ }^{1}$, indicando uma transformação na sua estrutura produtiva paralela à viabilização de uma inserção internacional diferenciada quando comparada a outros países de industrialização tardia.

Como desdobramento deste processo de reorientação da inserção internacional potencializado a partir do ingresso da China na Organização Mundial de Comércio (OMC) em 2001, observou-se a concomitante transformação do tecido industrial local. Essa transformação decorre de um modelo articulado pelo Estado capaz de fazer com que o "Made in China" fosse gradativamente desassociado dos produtos de baixa qualidade e baixa capacidade de inovação.

No que diz respeito a qualidade das exportações, trabalhos como Schott (2004), Hausmann, Hwang e Rodrik (2007), Hummels e Klenow (2005), Hallak (2006) e Hiratuka e Cunha (2011), Gomes e Silva (2020) encontraram que países desenvolvidos tendem a exportar produtos de maiores preços e isso se relaciona com a maior complexidade nos produtos de sua pauta exportadora. Tal movimento também se relaciona às características das estruturas produtivas nacionais, já que os autores estabelecem uma relação entre preços unitários maiores e uma estrutura produtiva mais intensiva em bens sofisticados, como maior esforço inovativo e a construção de ativos intangíveis.

Nesta perspectiva, o objetivo deste trabalho é compreender como as mudanças na estrutura produtiva da China impactaram os preços de bens industriais exportados pelo país entre 2001 e 2017, considerando este fator como uma variável de qualidade das exportações. A hipótese é que as transformações na estrutura produtiva chinesa, no referido período, viabilizadas por uma estratégia de desenvolvimento, que busca construir vantagens comparativas baseadas na eficiência dinâmica (nos sentidos schumpteriano e keynesiano, conforme Cimoli, et al., 2006), têm viabilizado a reorientação da pauta exportadora em direção a produtos mais nobres, com maior qualidade e, portanto, maiores preços. Deste modo, observar-se-ia no período uma redução do diferencial de preços relativos das exportações de produtos industriais chineses face aos preços destes mesmos produtos exportados por outros países.

Para isto, a metodologia deste trabalho propõe calcular as margens intensiva e de qualidade de acordo com o método utilizado por Hummels e Klenow (2005) e classificados de acordo com os tipos de tecnologia: intensivas em escala, diferenciadas e baseadas em ciência. Justifica-se tal recorte devido ao fato dos produtos característicos destes setores serem aqueles com maior

\footnotetext{
${ }^{1}$ A partir das contribuições expressas em Kaldor (1966), este trabalho entende por tecnologias mais nobres aquelas que estejam associadas a produtos que apresentem: i) elevado dinamismo no mercado internacional; ii) elevadas elasticidades-renda da demanda; iii) elevados encadeamentos em seus processos produtivos; iv) elevadas intensidades tecnológicas; v) elevado valor agregado e vi) capacidade de geração de empregos com elevadas remunerações.
} 
capacidade de demonstrar o aumento do grau de sofisticação da pauta de exportações chinesas. Neste cenário, este artigo divide-se em quatro seções em que se apresentam: 1) referencial bibliográfico a respeito das mudanças na estrutura produtiva chinesa, além da literatura sobre qualidade das exportações; 2) metodologia de análise; 3) a discussão dos resultados e as 4) considerações finais.

\section{Revisão Bibliográfica}

\subsection{Mudanças na Estrutura Produtiva Chinesa}

A China se tornou um importante receptor de investimentos, na Ásia e no mundo. Estes investimentos desempenharam papel crucial na modernização do país. Durante a década de 1970, diversas mudanças na economia, como um cenário de maior acirramento da competição global, conjugado com altas taxas de inflação, instabilidade do arranjo político e econômico, mudanças no sistema financeiro e baixo crescimento levaram as grandes empresas a uma busca por rentabilidade de curto prazo. Este processo, baseado na maior racionalização e reduções de custos, culminou na internacionalização de empresas transnacionais, em especial aquelas dos setores diferenciados (que são mais passíveis de modularização, apresentam grandes escalas e ciclos curtos de produto), em direção a países periféricos, em especial na Ásia. A partir da segmentação do processo de produção e outsourcing de parte de suas atividades, tais firmas poderiam gozar de menores custos de produção, bem como adquirir vantagens de economias de escala e escopo (Sarti, \& Hiratuka, 2010; Crotty, 2002; Lazonick, 2000).

Como forma de atrair o capital produtivo para o território chinês, o governo atuou de diversas formas e, principalmente, por meio da criação das Zonas Econômicas Especiais (ZEEs), em que o Estado provia: câmbio artificialmente depreciado, isenção tributária, financiamento estatal abundante para novos empreendimentos a taxas de juros reduzidas. Além disso, contava-se com mão de obra barata e relativamente qualificada. Portanto, estes fatores se configuravam como atrativos importantes para produzir a custos menores, dado o cenário de acirramento da competição internacional (Milaré, 2011).

Como aponta Acioly (2005), durante a década de 1980, os investimentos estrangeiros concentravam-se nas atividades de prospecção geológica, na indústria manufatureira intensiva em trabalho (indústria tradicional, especialmente têxtil e confecções de roupas) e no setor de serviços (atividades imobiliárias). A partir de 1986, o governo chinês tomou uma série de medidas para mudar a estrutura setorial dos investimentos diretos externos recebidos, dirigindo-os para a indústria de transformação e para os setores de alta tecnologia. Desse modo, o IDE (Investimento Direto Externo) direcionado ao setor primário reduziu de 40,9\% em 1988 para $3,1 \%$ em 1993 e o setor manufatureiro passou a ser o principal destino dos IDEs.

Nesse sentido, entende-se que o Estado chinês buscou atrair e orientar esses investimentos para implementar políticas que incentivassem a formação e/ou modernização do parque industrial, impulsionando o catching up tecnológico. Isto é, via IDE, a China buscou: (i) modernizar seu parque industrial; (ii) aumentar participação no comércio internacional e (iii) obter acesso a tecnologias mais avançadas (Acioly, 2005). Assim, percebe-se que a trajetória de atração de IDE chinês se faz singular na medida em que se afasta do típico modelo mexicano de empresas que atuam como maquiladoras (Pinto, 2011), utilizando-o, ao contrário, como um instrumento de uma política industrial mais ampla, voltada para um modelo de desenvolvimento econômico. 
Dessa forma, o Estado chinês procurou controlar em quais setores haveria participação estrangeira, priorizando aqueles relacionados à exportação e bens sofisticados. Dessa forma, foi possível que as empresas chinesas pudessem, em alguma medida, apropriar-se de capacidades tecnológicas importantes para o processo de catching up tecnológico. Isso se mostra pelos exemplos citados:

\begin{abstract}
$\mathrm{Na}$ verdade, embora as empresas chinesas ainda participem das cadeias globais em posições inferiores - capturam baixo valor agregado -, o governo chinês tem utilizado instrumentos de financiamento e de política industrial com o objetivo de fortalecê-las, para que estas firmas - tais como a Lenovo (computadores), a Huawei (equipamentos de telecomunicações), a Haier (eletrodomésticos e eletroeletrônicos) e a Chery Automobile (automóveis) - se tornem players no mercado mundial e, consequentemente, subam na hierarquia da cadeia de valor global. Certamente esse caminho pode ser muito longo, mas há evidências de que as estratégias adotadas pelo governo chinês têm conseguido gerar processo de catching up, que ainda está em suas fases iniciais (Pinto, 2011, p. 52).
\end{abstract}

Assim, percebe-se que a China passou por diversas mudanças, com destaque às estruturais, que a levaram a ser um player importante no comércio internacional. Com isso, o país passou de um grande exportador de bens intensivos em trabalho para bens mais sofisticados.

Nesse arcabouço, destaca-se Rodrik (2006) que buscou entender a relação entre a cesta exportada pelos países e nível de renda. O comportamento da China foi considerado um outlier da pesquisa à medida que o país tinha uma cesta de exportação três vezes maior que o esperado para sua renda per capita. Assim, em 2003, essa relação ainda se encontrava em níveis abaixo da Coreia do Sul, porém, afastou-se da Índia, país que a China se mostrava próxima em 1992, associado a essa relação (cesta exportada e nível de renda).

Além disso, Rodrik (2006) fez uma relação entre a cesta exportadora e o capital humano, de forma a avaliar a teoria associada à dotação de fatores. O resultado é que um país como Bangladesh, que apresentava características semelhantes à China, com mão de obra abundante e capital humano relativamente escasso, obteve uma cesta exportadora com produtividade $50 \%$ menor que a chinesa. Nesse sentido, o autor aponta para fatores idiossincráticos relativos à sofisticação chinesa, ou seja, a cesta chinesa apresenta bens mais intensivos em tecnologia, que não guardam conexão com sua dotação de fatores (Rodrik, 2006).

Lardy (2004) argumenta que a China, na verdade, exporta maior conteúdo tecnológico, porém, nos elos menos nobres da cadeia. Esses acabam por agregar pouco valor, servindo mais como uma plataforma de exportação. Rodrik (2006) mostra que o conteúdo exportado é elevado em relação ao PIB per capita chinês. Em outras palavras, países com renda similar à chinesa exportariam uma cesta de menor produtividade do que a cesta real chinesa.

Por sua vez, Schott (2008) faz uma comparação entre as cestas de exportação dos parceiros comerciais dos Estados Unidos (EUA). A partir deste trabalho é possível verificar que a cesta de exportação chinesa se aproxima dos países pertencentes à OCDE. O autor mostra, a partir de simulações econométricas, que a China apresenta uma cesta de exportação mais próxima aos países da OCDE do que países com características semelhantes à China como, por exemplo, Bangladesh. Outro aspecto importante é que, ao longo dos anos, a diferença entre as exportações chinesas e da OCDE diminuíram. 
Schott (2008) também apresentou uma análise sobre a evolução dos preços das exportações chinesas e a evidência empírica demonstrou que existe uma relação positiva entre países de maior renda e exportações a preços maiores. Logo, a maior aproximação da China à cesta da OCDE levaria o país a exportar produtos mais caros. No entanto, o autor encontrou que a China apresenta preços mais baixos de exportação que os países da OCDE. Esta verificação se repete ao avaliar a indústria, e aliado a isso, os preços chineses se tornam mais baratos ao longo do período entre 1980 e 2000.

No que diz respeito as exportações chinesas, a entrada do país na OMC, em 2001, requereu densas reformas ${ }^{2}$ para que se adequasse às normas da organização e facilitasse as negociações comerciais. Por outro lado, possibilitou uma densa expansão das exportações. Além disso, como mostra o Gráfico 1 há um esforço de orientação das exportações chinesas para setores com maior intensidade tecnológica.

Gráfico 1 - Participação das exportações de alta intensidade tecnológica ${ }^{3}$ da China em relação aos EUA e ao mundo $(\mathrm{em} \%)^{4}$

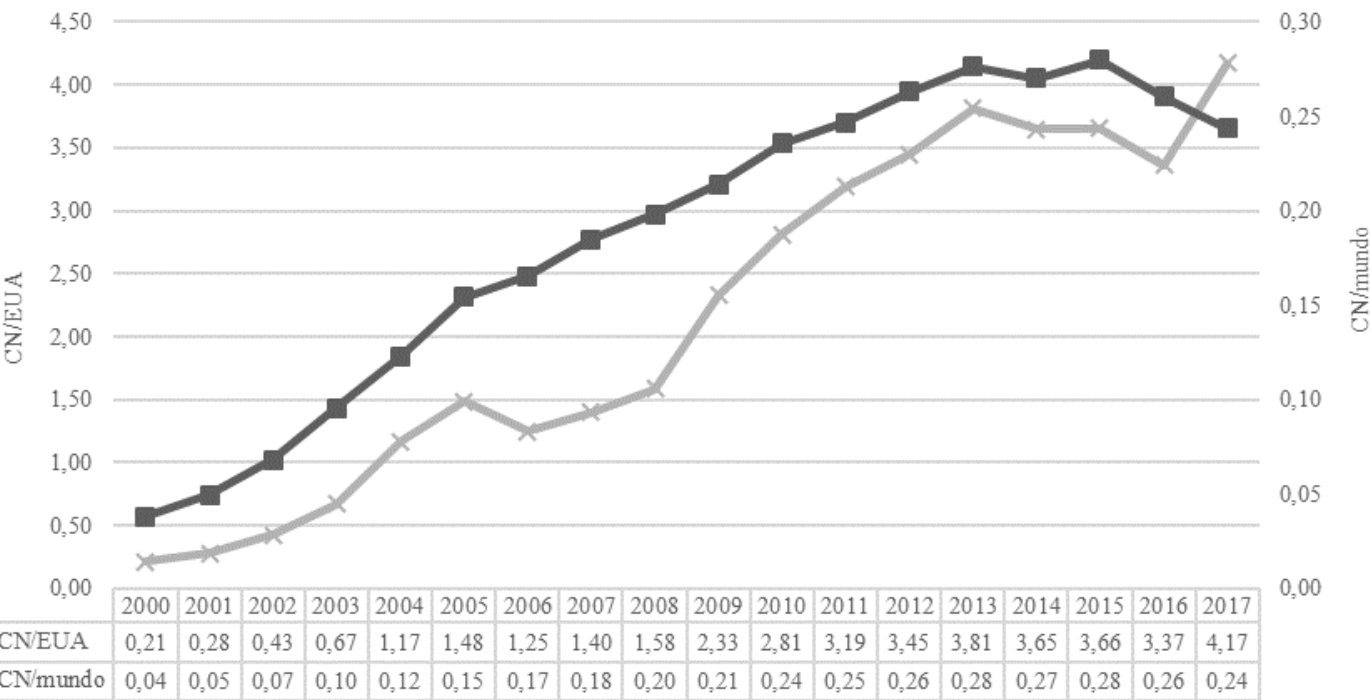

Fonte: Banco Mundial, elaboração própria (2020).

Nota-se, no gráfico 1, um aumento nas exportações de produtos com alta intensidade tecnológica quando comparado aos EUA. As exportações da China em relação aos EUA, em valores percentuais, são de 0,21 em 2000 e 4,17 em 2017. Segundo esse indicador, para cada bem exportado de alta intensidade tecnológica pelos EUA, a China exportou pelo menos quatro em 2017. Observa-se que quando a comparação é feita entre a China e o mundo

\footnotetext{
${ }^{2}$ Milaré (2011) detalha algumas reformas apontando para: (1) o fim do mercado de swaps e liberalização ao acesso a outras moedas; (2) a substituição das cotas de importações por teto de tarifas, em que a tarifa de importação seria baixa para um pequeno volume de importação - nesse contexto, tal medida representa uma forma de liberalizar o acesso aos produtos internacionais de forma atenuada e por fim, (3) o comprometimento em criar restrições à cópia e proteger a propriedade intelectual.

${ }^{3}$ Segundo o Banco Mundial, exportações de alta tecnologia são produtos com elevada intensidade de P\&D, como a indústria aeroespacial, computadores, produtos farmacêuticos, instrumentos científicos e equipamentos elétricos.

${ }^{4}$ Destaca-se que 132 países compõem o indicador intitulado "mundo". Foram mantidos na soma os países que apresentaram no máximo dois dados faltantes entre 2000 e 2017.
} 
o país asiático também apresentou uma taxa crescente exibindo uma relação de 0,04 em 2000 e 0,24 em 2017. O fato da pauta exportadora estar direcionada para produtos com maior intensidade tecnológica indica potenciais de inovação e ganhos de produtividade.

Além das exportações, a China também mostrou um avanço significativo no valor adicionado da indústria de transformação, de aproximadamente 250 bilhões de dólares em 2000 para aproximadamente 728 bilhões de dólares em 2017, segundo o Banco Mundial. Para além do valor total da transformação industrial, o gráfico 2 apresenta a decomposição deste valor por tipos de tecnologia ao longo dos anos. Ressalta-se que se deve considerar o processo de expansão do valor adicionado da indústria de transformação, isto é, as tecnologias que mantém sua participação ao longo dos anos apresentam crescimento igual ao do valor adicionado manufatureiro total.

Gráfico 2 - Valor adicionado pelo setor industrial chinês por tipo de tecnologia ${ }^{5}$ - deflacionado pelo índice de preços dos produtos manufaturado com base no ano 2000 (\%)

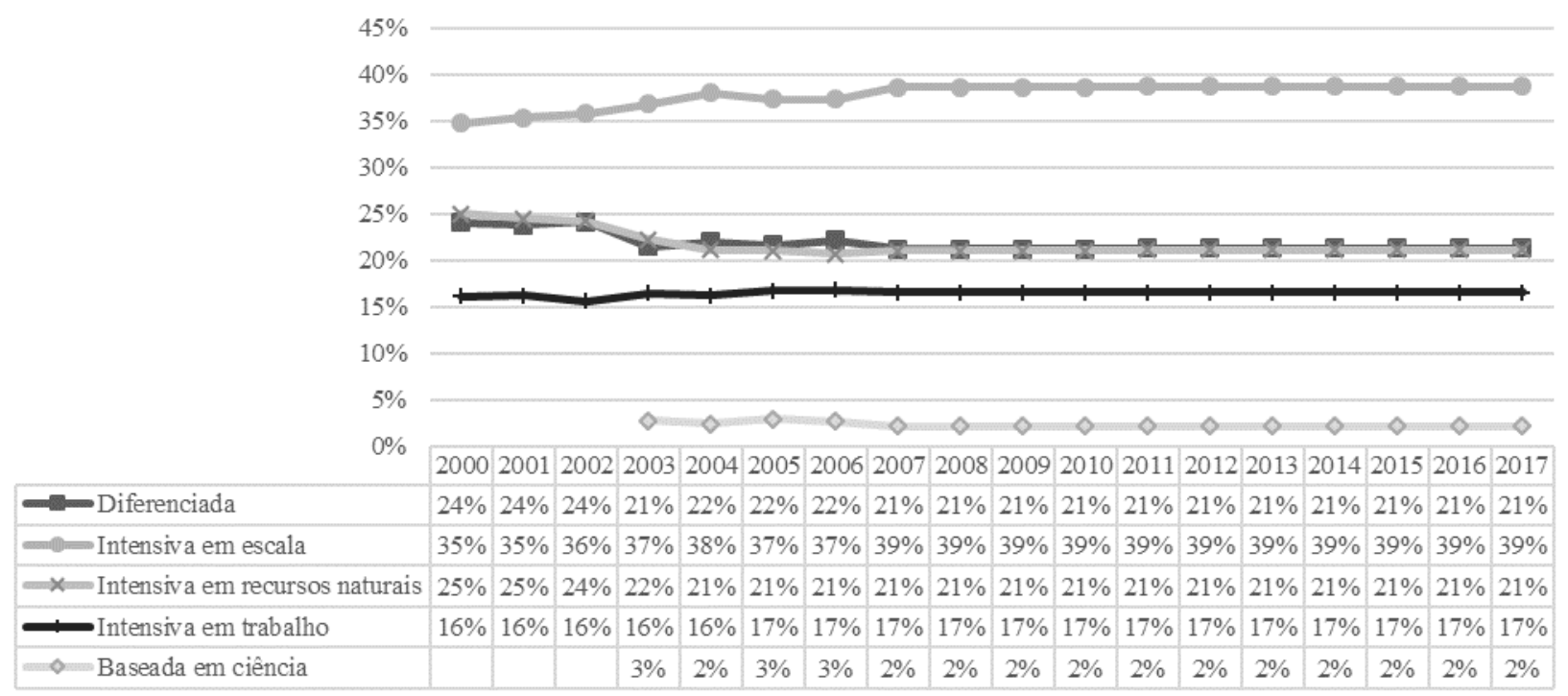

Fonte: INDSTAT2 2020 ISIC Revision 3 (UNIDO), elaboração própria (2020).

Pode-se observar pelo gráfico 2 a elevada participação e manutenção, ao longo dos anos 2000,da tecnologia intensiva em escala e diferenciada. Nesse sentido, ressalta-se Nassif (2008) ao avaliar que essas tecnologias possuem maior intensidade da relação capital/trabalho e maior sofisticação tecnológica dos seus produtos. Isto é, tratam-se de vetores de difusão da inovação na economia (p. 85). Desta forma, os dados encontrados corroboram o estudo de Nonnenberg e Mesentir (2012) ao analisarem que a China evoluiu de um país montador para um país produtor de partes e acessórios, aumentando o valor adicionado ao seu produto doméstico 6 .

\footnotetext{
${ }^{5}$ O índice foi extraído da tabela 5.1 do ano de 2019 da base de estatística da China. O dado disponibilizado considera o ano anterior como base, logo para o deflacionamento retirou-se o índice de uma base relativa e atribuiu-se uma base fixa, para o ano de 2000.

${ }^{6}$ Nassif (2008) também menciona os setores intensivos em ciência como portadores de tais características. No entanto, nota-se que no caso chinês ainda há um gargalo nesta tecnologia.
} 
Visando melhorar a articulação do seu modelo de desenvolvimento, a China buscou enfatizar atividades inovadoras, que visassem superar o gap existente em relação às regiões líderes. Dessa forma, a partir dos anos 2000, junto a expansão das exportações, o Estado chinês engendrou um novo ciclo da política industrial, voltado a um programa de inovação "autóctone"7 direcionado às especificidades da economia local. O intuito básico era fazer que a China se transformasse em um país com crescimento e desenvolvimento embasados pela inovação em 2020.

De acordo com Cassiolato e Podcameni (2015) a estratégia consistia em utilizar o mercado interno para desenvolver novas trajetórias tecnológicas. Os autores ressaltam que a política de inovação priorizou o desenvolvimento de tecnologias voltadas para a construção de um novo paradigma tecnológico que atendesse as especificidades locais, fugindo dos padrões do "centro",

Gomes (2017) ao avaliar a estrutura de dispêndio em $\mathrm{P} \& \mathrm{D}^{9}$ na China, para o ano de 2014, observou-se que há uma concentração dos gastos nos setores intensivos em escala, diferenciado e baseado em ciência. Logo, percebe-se uma busca para fazer com que o "Made in China" fosse gradativamente desassociado dos aspectos de baixa qualidade e baixa capacidade de inovação. Nesse contexto, destaca-se que:

(...) a percepção de produtos "Made in China" a "preços chineses", isto é, de baixa qualidade, muito baratos, fabricados por estrangeiros ou por empresas chinesas pouco experientes em manufatura, aos poucos migra para a constatação de produtos desenvolvidos e criados na China, com valores adicionados no país, por meio de inovações em processos e tecnologia, não apenas por multinacionais de fora, mas também por um crescente número de empresas genuinamente chinesas. Com isso, a China não se torna apenas o workshop of the world (GAO, 2011), mas um player competitivo em tecnologia, inovação e valor agregado (Masiero, \& Coelho, 2014, p.154).

Por sua vez, o plano "Made in China 2025" (2017) avalia que apesar da China ter produzido e montado $28 \%$ dos automóveis, $41 \%$ dos navios, $80 \%$ ou mais dos computadores, $90 \%$ ou mais dos celulares, em 2015, os processos em muitos destes setores são indústrias de baixo valor agregado, intensivas em energia e altamente poluentes. Com isso, o relatório afirma que o país planeja atualizar sua base industrial e competir em segmentos mais avançados, isto é, em elos das cadeias de valor da indústria 4.0, que envolvem digitalização da produção, uso de computação em nuvem e conexão com interação entre humanos e robôs.

\subsection{Relação entre Preços de Bens Exportados e Catching up}

Nessa seção, busca-se compreender a partir de uma breve revisão da literatura, como as mudanças engendradas na China foram capazes de mudar a estrutura produtiva do país em direção a bens mais intensivos em tecnologia, bem como seus impactos sobre os preços de bens industriais exportados pelo país. Nesse sentido, há diversos trabalhos na literatura que buscam estabelecer relações entre os preços dos bens exportados e a estrutura produtiva dos países produtores.

\footnotetext{
7 "Um produto de inovação autóctone é definido como aquele cujos direitos de propriedade pertencem a uma empresa chinesa e a marca comercial seja registrada inicialmente na China" (CASSIOLATO, 2013, p.76).

${ }^{8}$ Centro aqui é para designar as relações centro-periferia abordado pela literatura tradicional.

${ }^{9} \mathrm{O}$ autor utiliza dados da OCDE.
} 
Nesses termos, Schott (2004) encontrou três relações importantes: (i) uma relação de valor unitário maior das exportações para países de maior PIB per capita; (ii) os valores unitários estão correlacionados positivamente com a intensidade de capital utilizado em sua produção; (iii) países desenvolvidos apresentam um aumento do valor unitário, ao longo do tempo. Porém, o autor avaliou que, embora os países exportassem o mesmo produto, esses possuíam preços diferentes. Afirma-se que esta diferença entre valores unitários estava associada à qualidade.

Hummels e Klenow (2005) apoiaram suas análises no padrão das exportações pela decomposição em margens extensiva (exportações em novas variedades de produtos), intensiva (intensidade das exportações de bens que já estão sendo exportados) e de qualidade. Os resultados, portanto, reforçam o argumento de que países com maior renda mostram tendência a exportar maiores volumes e variedades de produtos, além de apresentar qualidade superior dos bens advindos de países com menor nível de renda.

Hausmann, Hwang e Rodrik (2007), por outro lado, investigaram a qualidade da pauta exportadora, por meio de indicador de sofisticação das exportações, com dados de exportação para o período de 1992 a 2003. Os autores fornecem evidências que países desenvolvidos (maior renda) exportam produtos identificados como de maior qualidade.

Hallak (2006) em uma análise empírica foca nos determinantes da qualidade pelo lado da demanda e testa, em particular, o efeito da demanda por qualidade sobre os fluxos bilaterais de comércio desagregados setorialmente. $O$ autor encontrou evidências que a demanda por qualidade varia de acordo com a renda do país importador e conclui que o comércio será mais intenso entre países que possuem rendas per capita semelhantes. Dessa forma, os países ricos gastam uma parcela maior de sua renda em produtos de alta qualidade e produtos de importação de maior qualidade.

Para Aiginger (1997, apud Hiratuka, \& Cunha, 2011), por exemplo, a qualidade está ligada à dinâmica de concorrência dos mercados. Para o autor, a concorrência que se baseia na qualidade é mais acirrada e diferente da concorrência por preços. Além disso, a concorrência via qualidade se baseia no alcance de mercados que sejam mais inelásticos, ou seja, que apresentam menor sensibilidade de preços em sua demanda. Isso se dá por meio da inovação, diferenciação de produtos, marketing, dentre outros. Em outras palavras, a concorrência se dá pela busca da construção de ativos intangíveis capazes de se transformarem em ganhos de monopólios.

Schott (2004) complementa este aspecto avaliando que o aumento do valor unitário poderia ser explicado sob duas formas: maior capacidade de inovação e diferenciação dos produtos e maior intensidade de capital na produção. Logo, geralmente são os países desenvolvidos que possuem maior tecnologia empregada e, a partir disto, conseguem construir vantagens que os diferenciam de outros produtores via inovação, podendo auferir maiores lucros.

A fim de compreender a questão da qualidade do comércio internacional chinês, Hiratuka e Cunha (2011) utilizaram a metodologia mostrada por Fontagné, Gaulier e Zignago (2008) e realizam a divisão do fluxo bilateral de comércio em segmentos de qualidade (produtos de baixa ou média e alta ou média qualidade) visando comparar o valor unitário do produto do país para um determinado mercado de destino. Pode-se verificar que, embora a China tenha aumentado a participação dos fluxos de baixa qualidade também o fez nos segmentos de alta qualidade. Nos segmentos intensivos em trabalho e em recursos naturais houve diminuição da produção de alta qualidade. Nos setores intensivos em trabalho houve 
decréscimo, inclusive na média qualidade. Os setores nos quais se verificaram maior aumento dos fluxos de alta e média qualidade foram em fornecedores especializados.

Aplicando a mesma metodologia, Gomes (2017) constatou que os produtos de origem chinesa apresentaram maiores valores unitários de exportação, uma vez que a indústria tem buscado modificar sua estrutura direcionada a exportação com maior nível de qualidade. $\mathrm{O}$ autor também encontrou para o período de 1995-2014: i) aumentos na exportação de alta qualidade; ii) as exportações de baixa qualidade caíram em 16 pontos percentuais nos setores diferenciados e baseados em ciência; iii) nos setores intensivos em trabalho houve queda de 10 pontos percentuais e em intensivos em escala houve queda de 6 pontos percentuais. Esses resultados sinalizam uma melhora nos níveis de qualidade das exportações chinesas no período.

Schott (2008) ainda encontrou evidências que a China apresenta uma cesta exportadora mais próxima à de países desenvolvidos, como foi apresentado na seção anterior. Além disso, a diferença entre essa cesta e a dos países da OCDE vem diminuindo. No entanto, embora a China apresente uma pauta semelhante à de países da OCDE, ao analisar os preços, ao longo do tempo, verifica-se que estes são mais baixos, para todas as indústrias, além de diminuírem ao longo do tempo, de 1980 a 2000.

Nesse sentido, Gao, Whalley e Ren (2014) encontram resultados semelhantes ao de Schott (2008). Os autores verificam como as margens intensiva e extensiva, além dos preços colaboram para o aumento das exportações chinesas. Desta forma, avaliaram que entre 1995 a 2010, o aumento das exportações chinesas se deveu, em 66,8\%, à margem intensiva, ou seja, ao volume exportado. Em seguida, os preços colaboram com 18,8\% e a margem extensiva, com $14,3 \%$.

A fim de estabelecer uma relação entre a mudança na pauta exportadora e o catching up tecnológico, trabalhos como Kaldor (1966), Archibugi e Michie (1998) e Hausmann, Hwang e Rodrik (2007) afirmam que a maior participação de bens manufaturados com maior conteúdo tecnológico na pauta de produção e exportação implicará em rendimentos crescentes para a produção, elevando os encadeamentos produtivos, induzindo ao aumento da produtividade e geração de externalidades por meio da difusão de conhecimento e tecnologia (dada a capacidade de absorção por partes das empresas e necessidade de adaptação aos padrões internacionais de produção). Com isso, ter-se-ia, por fim, um círculo virtuoso de crescimento que pode proporcionar aos países em desenvolvimento realizarem o catching up.

Em suma, diversos trabalhos encontraram que países desenvolvidos tendem a exportar produtos de maiores preços e isso se relaciona com a maior complexidade nos produtos de sua cesta exportadora. Ademais, relaciona-se também a sua estrutura produtiva, já que os autores estabelecem uma relação entre preços unitários maiores e uma estrutura produtiva mais intensiva em bens sofisticados.

No caso chinês, existe uma mudança da pauta exportadora em direção a bens mais intensivos em tecnologia, além de um aumento dos preços de bens industriais exportados, o que aponta na direção de bens de maior qualidade. No entanto, nota-se que o país ainda permanece, em grande parte, nos fluxos de baixa qualidade, e exportando, em ambos os casos, grandes volumes. Para verificar estes pontos, em especial o nível de volume e qualidade dos produtos exportados da China em relação ao comercio mundial, a seção seguinte apresenta a metodologia empregada por esse trabalho. 


\section{Metodologia}

\subsection{Base de Dados}

Os dados foram obtidos por meio da base UN Comtrade Data base para os anos de 2001 e 2017. Foram coletados dados de 29 exportadores, que correspondem a $81,82 \%{ }^{10}$ do total exportado, no comércio mundial, no ano de 2017. No entanto, em função da falta de dados para Tailândia e Arábia Saudita, a amostra foi reduzida para 27 países. Desta forma, esse mesmo grupo de 27 países será utilizado para a comparação com o ano de $2001^{11}$.

Com relação aos importadores serão utilizados grupos distintos para o ano de $2001 \mathrm{e}$ para o ano $2017^{12}$, considerando para os dois anos 24 importadores. Para o ano de 2001, o grupo de importadores compreende 77,90\% do total importado no mundo, enquanto que 2017 foi de $76,38 \%$. Ou seja, a escolha tanto dos países exportadores quanto os países importadores foram com base na sua importância no comércio global.

O ano de 2001 foi escolhido devido a entrada da China na OMC. Vale ressaltar que a China ambicionava sua entrada na OMC, devido à possibilidade de elevar sua inserção no comércio internacional. Ao entrar na OMC, a China teria maior acesso aos mercados dos demais países - desenvolvidos e em desenvolvimento - principalmente nas indústrias de manufatura leve, seu principal setor de exportação. Em 1994, a China exportava US\$ 121 bilhões; em 2001, já passava dos US\$266,1 bilhões; e, em 2008, atingiu US\$ 1,43 trilhões. Em 1982, o comércio exterior da China representava 1,1\% do mundial; em 1992 este já atingia 2,3\%; em 2001, ano de sua efetiva entrada na OMC, representava 4,3\%; e, em 2010, atingiu a marca de $10,4 \%$, consolidando-se como o maior exportador mundial de bens do mundo (MILARÉ, 2011).

Para 2001 e 2017 a base de dados apresentou um total de 1.953 .120 observações. Para evitar erros de mensuração e contornar as limitações da base, algumas transações foram retiradas. Esse procedimento contou com a estratégia de omitir os valores menores que US\$ 250 e maiores que US\$ 1 bilhão, como feito em processo análogo por Baldwin e Harrigan (2011) e replicados por Gomes e Oliveira (2020). Um total de 139.238 observações foi registrado na base de dados como zero (não reportado) ${ }^{13}$ também foram retirados. Vale destacar que as informações de categorias exportadas foram reportadas a seis dígitos, segundo o sistema harmonizado (HS).

10 Países: China, EUA, Alemanha, Japão, Holanda, Coreia do Sul, Hong Kong, França, Itália, Reino Unido, Bélgica, Canadá, México, Singapura, Rússia, Espanha, Emirados Árabes, Suíça, Índia, Tailândia, Polônia, Austrália, Arábia Saudita, Brasil, Malásia, Vietnã, República Tcheca, Indonésia, Áustria.

11 Para o ano de 2017, não há dados de exportação a seis dígitos, para Tailândia e Arábia Saudita. Isso fez com que a amostra de países fosse reduzida para 27 países, correspondendo a 78,84\% do total exportado pelo mundo. Ademais, as informações foram coletadas a partir dos dados do Trade Map, das Nações Unidas.

12Em 2017 os países são: EUA, China, Alemanha, Japão, Reino Unido, França, Hong Kong, Holanda, Coréia do Sul, Itália, Índia, Canadá, México, Bélgica, Espanha, Singapura, Emirados Árabes, Suíça, Turquia, Polônia, Rússia, Tailândia, Austrália, Vietnã. Em 2001 os países são: EUA, China, Alemanha, Japão, Reino Unido, França, Holanda, Hong Kong, Coréia do Sul, Índia, Itália, México, Canadá, Bélgica, Espanha, Singapura, Suíça, Polônia, Vietnã, Tailândia, Rússia, Austrália, Turquia, Malásia.

13 Os dados podem ser reportados de acordo com as características do produto. No sítio institucional do UN COMTRADE as unidades dos produtos podem ser: não reportados (não foi classificado), área em metros quadrados, energia elétrica em milhares de quilowatts-hora, comprimento em metros, número de itens, número de pares, volume em litros, peso em quilogramas, milhares de itens (milheiro), número de pacotes, dezenas de itens, volume em metros cúbicos e peso em quilates. 


\subsection{Classificação das atividades}

As categorias de produtos foram classificadas de acordo com fator competitivo predominante da OCDE (1987). Nesse sentido, todos os produtos analisados nesse artigo são reagrupados em três tipos de tecnologia: Intensiva em Escala, Diferenciada e Baseada em Ciência, seguindo a classificação análoga a Borbély (2005), que permite avaliar a qualidade das variedades exportadas em cada categoria tecnológica.

\subsection{Margens Intensiva e de Qualidade}

Os cálculos das margens intensiva e de qualidade foram realizados de acordo com o método utilizado por Hummels e Klenow (2005). Este trabalho propõe incorporar mudanças temporais em que $t$ representa cada ano utilizado na amostra. Além disso, propõe-se incorporar a análise dos fluxos por tipos de tecnologia (g), como em Gomes e Silva $(2020)^{14}$. Isso permitiu uma análise mais criteriosa e minuciosa para cada segmento tecnológico a fim de avaliar os preços em geral de bens exportados, o nível de preços e volume de outros países que exportam no mesmo segmento tecnológico e ainda é possível caracterizar os principais importadores da China.

A margem intensiva corresponde ao volume dos bens de exportação de um país a um dado mercado em comparação com o volume médio negociado dos mesmos produtos exportados por uma economia de referência $k$. Na construção dos indicadores, a economia de referencia, $k$, seria o restante do mundo, enquanto $j$ é um país exportador selecionado e $m$ um país importador, em uma determinada categoria de produtos, $i$. Além disso, $p$ é o preço do bem e $x$ representa a quantidade.

Assim, a margem intensiva explicaria a quota de mercado que um país exportador $j$ obteve em seus mercados de importação $m$ em um conjunto comum de bens classificados de acordo com sua intensidade tecnológica $g$.

$$
I M_{j m g t}=\frac{\sum_{i \in I j m g t} p_{j m g i t} x_{j m g i t}}{\sum_{i \in I j m g t} p_{k m g i t} x_{k m g i t}}
$$

Para a construção do índice de preços (proxy de qualidade) não é considerado o preço unitário do produto de forma isolada, mas o preço de cada categoria exportada de $j$ para $m$ em relação ao preço médio do mesmo produto comercializado mundialmente, ou seja, na mesma categoria a seis dígitos do produto. Isso significa dizer que para uma determinada categoria $i$, a seis dígitos (HS6), seu preço foi comparado com todos os preços dos outros países exportadores daquele bem (preço médio da mesma categoria), para um país importador específico. Este processo é feito sucessivamente entre os países importadores e exportadores, para cada uma das categorias de produto, conforme mostra a Equação 2:

$$
P_{j m g t}=\prod_{i \in j m g t}\left(\frac{p_{j m i t}}{p_{k m i t}}\right)^{w_{j m i t}}
$$

O índice ainda é ponderado pela parcela das exportações de $j$ e $k$ para $m$. O peso $w_{j m i t}$ é calculado como a média logarítmica das parcelas de exportação (Equação 3 ). $s_{j m i t}$ é a

\footnotetext{
14 Gomes e Silva (2020) investigaram a qualidade (índice de preços), o volume (margem intensiva) e a diversificação (margem extensiva) dos produtos manufaturados no comércio mundial. Os autores incorporaram a variável de tempo (t) e tecnológica (g) no modelo proposto por Hummels e Klenow (2005).
} 
parcela de exportações de $j$ para $m$, na categoria de $i$, no período $t$, e $s_{k m i t}$ é a parcela do resto do mundo (países selecionados) nas exportações para $m$, na categoria $i$, para período $t$ :

$$
w_{j m i t}=\frac{\left(\frac{s_{j m i t}-s_{k m i t}}{\ln s_{j m i t}-\ln s_{k m i t}}\right)}{\sum_{i \in I_{j m i t}}\left(\frac{s_{j m i t}-s_{k m i t}}{\ln s_{j m i t}-\ln s_{k m i t}}\right)}
$$

Este trabalho além de agregar os produtos exportados por fluxos bilaterais, busca classificá-los em cinco categorias tecnológicas, entretanto, para fins deste trabalho, será considerado os três segmentos com maior conteúdo tecnológico. Dessa forma, o índice de preço é a média geométrica dos produtos manufaturados exportados pelo país $j$ para $m$ e de acordo com seu tipo de tecnologia $g$ (Equação 2).

As margens intensiva e de qualidade são calculadas por fluxos bilaterais e intensidade tecnológica, mas também podem ser agregadas por país exportador e tipo de tecnologia por meio de uma média geométrica das margens calculadas, como a seguir:

$$
I M_{j g t}=\prod_{m \in M_{-j}}\left(I M_{j m g t}\right)^{a_{j m g t}} \quad P_{j g t}=\prod_{m \in M_{-j}}\left(P_{j m g t}\right)^{a_{j m g t}}
$$

Dessa forma, conforme Gomes e Silva (2020) adaptou-se o ponderador de Hummels e Klenow (2005) em que $a_{\text {jmgt }}$ (Equação 5) é a média logarítmica da participação de $m$ nas exportações de $j$, classificada por tipo de tecnologia $g$ :

$$
a_{j m g t}=\frac{\left(\frac{d_{j m g t}-d_{k m g t}}{\ln d_{j m g t}-\ln d_{k m g t}}\right)}{\sum_{m \in M_{j m g t}}\left(\frac{d_{j m g t}-d_{k m g t}}{\ln d_{j m g t}-\ln d_{k m g t}}\right)}
$$

Em que $d_{j m g t}$ é a parcela das exportações de $j$ para $m$ no total das exportações de $j$, classificadas por segmento tecnológico, no ano $t$, e $d_{k m g t}$ representa a parcela das exportações do restante do mundo $k$ para $m$ no total das exportações de $k$, nas categorias classificadas por nível tecnológico que $j$ exporta, no mesmo ano $t$.

$$
d_{j m g t}=\frac{\sum_{i \in I_{j m g t}} p_{\text {jmigt }} x_{\text {jmigt }}}{\sum_{m \in M_{j g t}} \sum_{i \in I_{j m g t}} p_{\text {jmigt }} x_{j m i g t}} \quad d_{k m g t}=\frac{\sum_{i \in I_{j m g t}} p_{k m i g t} x_{k m i g t}}{\sum_{m \in M_{j g t} \sum_{i \in I_{j m g t}} p_{k m i g t} x_{k m i g t}}}
$$

Finalmente, a partir de tais procedimentos é possível ter uma melhor comparação das exportações entre os países não se limitando exclusivamente a uma análise focada entre países, mas também segmentando as exportações por intensidade tecnológica, evitando uma generalização das margens para todos os produtos manufaturados.

$\mathrm{Na}$ próxima seção são apresentados os resultados das margens intensivas e de qualidade por tipo de tecnologia para produtos manufaturados chineses comercializados internacionalmente.

\section{Resultados}

A análise dos resultados apresentados nesta seção terá como principal objeto as transformações no padrão de inserção internacional das exportações industriais chinesas. Para tal, conforme apresentado na metodologia, expressa na seção anterior, serão analisadas as evoluções da (i) margem intensiva e (ii) margem de qualidade - interpretada a partir da evolução dos preços relativos, conforme Hummels e Klenow (2005) e segmentados por tipo de tecnologia segundo Gomes e Silva (2020) - para os grupos (a) diferenciado, (b) intensivo 
em ciência e (c) intensivo em escala, conforme Borbély (2005), que é inspirado pela classificação tradicional da OECD (1987) e derivada de Pavitt (1984).

Tal esforço se concentrará nestes grupos por serem os principais vetores responsáveis pelas transformações na estrutura produtiva doméstica chinesa e por sua concomitante influência na transformação do padrão de inserção externa em direção a produtos tecnologicamente mais complexos e com maior valor agregado. A partir destes resultados, espera-se responder às seguintes questões:

1. É possível observar um aumento da participação das exportações chinesas (mensurada pela margem intensiva) para produtos intensivos em escala, em ciência e diferenciados nos mercados dos países analisados?

2. Esse eventual aumento da margem intensiva ocorre em paralelo a um aumento da sofisticação das exportações chinesas (expressa pelo indicador de qualidade) nesses setores?

3. A conjugação de aumento de margem intensiva e de qualidade nas exportações é um movimento generalizado e relativamente uniforme ou sua intensidade varia substancialmente segundo os diferentes tipos de relações comerciais com cada um dos países da amostra?

4. A despeito desta suposta tendência de sofisticação, o diferencial da qualidade das exportações chinesas tem se reduzido em relação à qualidade das exportações dos países tecnologicamente avançados?

5. Os movimentos identificados nos questionamentos anteriores ocorrem de maneira generalizada para os três tipos de agregação tecnológica utilizada (intensivos em escala, em ciência e diferenciados) ou assumem padrões diferentes em cada um deles?

Com relação aos produtos diferenciados (dentre os quais se inserem a maior parte daqueles do complexo eletrônico e segmentos sofisticados de máquinas e equipamentos com eletrônica embarcada), a primeira constatação é que entre 2001 e 2017, observou-se uma expressiva melhora na qualidade das exportações chinesas (com a evolução do indicador de 0,79 para 0,91, conforme tabela 1). Em outros termos, os preços médios chineses que representavam menos de $50 \%$ dos preços das exportações dos EUA em 2001, passaram a representar cerca de $64 \%$ em 2017.

Tabela 1: Evolução da margem intensiva e do índice de preços das exportações industriais chinesas, 2001 e 2017

\begin{tabular}{ccccccccc}
\hline & \multicolumn{4}{c}{ Margem Intensiva } & \multicolumn{3}{c}{ Margem de Qualidade } \\
\cline { 2 - 8 } Setores & $\mathbf{2 0 0 1}$ & $\mathbf{2 0 1 7}$ & $\mathbf{\Delta \%}$ & $\begin{array}{c}\text { Crescimento } \\
\mathbf{( \% )}\end{array}$ & $\mathbf{2 0 0 1}$ & $\mathbf{2 0 1 7}$ & $\begin{array}{c}\text { Índice de Preço } \\
\text { chinês/ Índice de } \\
\text { preço EUA, 2001 }\end{array}$ & $\begin{array}{c}\text { Índice de Preço } \\
\text { chinês/ Índice de } \\
\text { preço EUA, } \\
\mathbf{2 0 1 7}\end{array}$ \\
\hline $\begin{array}{c}\text { Intensivos em } \\
\text { Escala }\end{array}$ & 0.102 & 0.183 & 0.080 & 78.44 & 0.933 & 0.933 & 0.826 & 0.743 \\
$\begin{array}{c}\text { Baseados em } \\
\text { Ciência }\end{array}$ & 0.033 & 0.067 & 0.034 & 105.25 & 0.985 & 0.993 & 0.977 & 0.912 \\
Diferenciados & 0.087 & 0.213 & 0.125 & 143.29 & 0.791 & 0.915 & 0.471 & 0.637 \\
\hline
\end{tabular}

Fonte: Elaboração própria (2020).

Vale ressaltar que, apesar deste rápido e intenso movimento, a China ainda permanece entre os três países com menores índices de preços dos bens exportados - para os setores 
classificados como diferenciados entre os países analisados em 2017. Outra constatação interessante é a de que se observa um grande crescimento da participação das exportações chinesas em produtos diferenciados nos mercados dos países da amostra, o que faz com que ela se transforme no país com maior margem intensiva entre as principais economias do mundo, ao superar Japão, Alemanha e EUA (conforme tabela 2).

Tabela 2: Margem Intensiva e índice de preços de países selecionados no comércio mundial, setores intensivos em escala, baseados em ciência e diferenciados -2001 e $2017^{15}$

\begin{tabular}{|c|c|c|c|c|c|c|c|c|c|c|c|c|}
\hline \multirow{3}{*}{ Países } & \multicolumn{6}{|c|}{ Margem Intensiva } & \multicolumn{6}{|c|}{ Índice de Preços } \\
\hline & \multicolumn{2}{|c|}{$\begin{array}{l}\text { Intensivos em } \\
\text { Escala }\end{array}$} & \multicolumn{2}{|c|}{$\begin{array}{c}\text { Baseados em } \\
\text { Ciência }\end{array}$} & \multicolumn{2}{|c|}{ Diferenciados } & \multicolumn{2}{|c|}{$\begin{array}{l}\text { Intensivos em } \\
\text { Escala }\end{array}$} & \multicolumn{2}{|c|}{$\begin{array}{c}\text { Baseados em } \\
\text { Ciência }\end{array}$} & \multicolumn{2}{|c|}{ Diferenciados } \\
\hline & 2001 & 2017 & 2001 & 2017 & 2001 & 2017 & 2001 & 2017 & 2001 & 2017 & 2001 & 2017 \\
\hline Austrália & 0,034 & 0,018 & 0,025 & 0,019 & 0,005 & 0,004 & 1,216 & 1,220 & 1,037 & 1,076 & 1,355 & 1,421 \\
\hline Áustria & 042 & 0,030 & 0,037 & 0,034 & 0,026 & 0,019 & 1,122 & 1,181 & 1,038 & 1,015 & 1,277 & 1,141 \\
\hline Bélgica & 109 & 0,077 & 0,095 & 0,111 & 0,036 & 0,026 & 1,116 & 1,168 & 1,071 & 1,119 & 1,179 & 1,074 \\
\hline Brasil & 0,036 & 0,020 & 0,038 & 0,016 & 0,012 & 0,006 & 1,044 & 1,112 & 1,084 & 1,039 & 1,292 & 1,234 \\
\hline Canadá & 0,171 & 0,064 & 0,090 & 0,045 & 0,046 & 0,022 & 1,287 & 1,133 & 0,991 & 1,043 & 1,229 & 1,288 \\
\hline China & 0,102 & 0,183 & 0,033 & 0,067 & 0,087 & 0,213 & 0,933 & 0,933 & 0,985 & 0,993 & 0,791 & 0,915 \\
\hline Rep. Tcheca & 0,030 & 0,037 & 0,006 & 0,014 & 0,019 & 0,035 & 1,010 & 1,089 & 0,970 & 1,012 & 1,176 & 1,144 \\
\hline França & 0,144 & 0,079 & 0,216 & 0,136 & 0,086 & 0,045 & 1,125 & 1,174 & 1,032 & 1,039 & 1,356 & 1,225 \\
\hline Alem & 204 & 0,173 & 0,170 & 0,168 & 0,156 & 0,162 & 1,124 & 1,211 & 1,015 & 1,027 & 1,315 & 1,334 \\
\hline Hon & 0,118 & 0,051 & 0,051 & 0,066 & 0,091 & 0,073 & 1,170 & 1,261 & 0,996 & 1,012 & 1,061 & 1,094 \\
\hline Indonésia & 041 & 0,045 & 0,007 & 0,015 & 0,024 & 0,019 & 1,026 & 1,079 & 0,976 & 0,998 & 1,048 & 1,042 \\
\hline Itália & 0,089 & 0,063 & 0,086 & 0,077 & 0,064 & 0,050 & 1,081 & 1,159 & 1,017 & 1,026 & 1,210 & 1,141 \\
\hline Japão & 175 & 0,115 & 0,051 & 0,029 & 0,170 & 0,096 & 1,258 & 1,274 & 1,042 & 1,036 & 1,633 & 1,355 \\
\hline Core & 0,086 & 0,092 & 0,016 & 0,021 & 0,055 & 0,052 & 1,051 & 1,100 & 0,992 & 1,019 & 1,121 & 1,080 \\
\hline Malásia & 0,040 & 0,049 & 0,014 & 0,042 & 0,062 & 0,047 & 1,037 & 1,072 & 0,997 & 0,984 & 1,348 & 1,226 \\
\hline & 0,091 & 0,060 & 0,033 & 0,017 & 0,093 & 0,052 & 1,051 & 1,053 & 0,988 & 0,987 & 1,109 & 1,222 \\
\hline Ho & 0,078 & 0,062 & 0,058 & 0,074 & 0,068 & 0,055 & 1,093 & 1,119 & 1,023 & 1,074 & 1,443 & 1,289 \\
\hline Polônia & 0,043 & 0,042 & 0,013 & 0,023 & 0,022 & 0,025 & 0,984 & 1,037 & 0,990 & 1,012 & 1,006 & 1,082 \\
\hline Rús: & 0,044 & 0,031 & 0,009 & 0,013 & 0,006 & 0,004 & 1,061 & 1,120 & 0,997 & 1,038 & 1,983 & 1,865 \\
\hline Índia & 0,018 & 0,044 & 0,017 & 0,033 & 0,005 & 0,012 & 0,970 & 1,158 & 0,916 & 0,998 & 1,110 & 1,087 \\
\hline Singapu & 0,079 & 0,050 & 0,048 & 0,083 & 0,098 & 0,055 & 1,144 & 1,332 & 0,997 & 1,044 & 1,303 & 1,514 \\
\hline Vietnã & 0,008 & 0,017 & 0,001 & 0,004 & 0,006 & 0,034 & 1,037 & 1,082 & 0,993 & 1,015 & 1,152 & 1,231 \\
\hline Espanha & 0,076 & 0,044 & 0,044 & 0,050 & 0,024 & 0,015 & 1,018 & 1,040 & 0,995 & 1,009 & 1,120 & 1,030 \\
\hline Suíça & 0,040 & 0,028 & 0,229 & 0,168 & 0,030 & 0,023 & 1,465 & 1,685 & 1,198 & 1,307 & 1,747 & 1,759 \\
\hline Emira & 0,052 & 0,017 & 0,012 & 0,024 & 0,036 & 0,005 & 1,004 & 1,632 & 1,034 & 1,056 & 1,007 & 1,106 \\
\hline Reino Unido & 0,077 & 0,052 & 0,154 & 0,098 & 0,074 & 0,036 & 1,276 & 1,333 & 1,045 & 1,080 & 1,488 & 1,249 \\
\hline EUA & 0,111 & 0,173 & 0,359 & 0,165 & 0,170 & 0,159 & 1,129 & 1,257 & 1,009 & 1,089 & 1,681 & 1,436 \\
\hline
\end{tabular}

Ao se analisar a evolução das exportações chinesas de produtos diferenciados a partir de sua relação bilateral com os países examinados, entre 2001 e 2017, novamente se observa uma tendência bastante disseminada de aumento da relevância chinesa nestes mercados (via

\footnotetext{
${ }^{15}$ A Arábia Saudita não estava disponível no ano de 2017, levando a exclusão do país na apresentação.
} 
incremento da margem intensiva), com destaque para os casos de Hong Kong, Japão e Vietnam e Índia.

Merece destaque também o fato de a variação da qualidade das exportações chinesas (expressa pelo indicador de preços) ser muito pequena segundo países e regiões, a despeito do fato de os países asiáticos invariavelmente apresentarem os maiores indicadores de qualidade. Ou seja, não parece haver uma clara relação entre uma maior qualidade das exportações e o nível de renda médio do país importador para os produtos diferenciados. Por fim, denota-se que tal movimento não é restrito aos países asiáticos, uma vez que o crescimento da penetração e a preços bastante semelhantes, também ocorre de maneira sistemática em países desenvolvidos. Esse movimento, por sua vez, é mais um elemento na direção de confirmar o aumento do grau de sofisticação da estrutura produtiva chinesa (vide anexo 1).

Nos setores baseados em ciência, o crescimento da margem intensiva chinesa no período foi de mais de $105 \%$. Apesar deste movimento, este é o bloco de setores nos quais a relevância relativa das exportações chinesas é a menor para a economia mundial, quando comparado aos demais tipos de tecnologia analisados. A título de ilustração verifica-se que, para estes, a margem intensiva chinesa era menos de 10\% da margem dos EUA em 2001, e $39 \%$ em 2017.

Com relação à qualidade das exportações, a China ainda se concentra entre os três países com menores índices de preços na amostra. Entretanto, vale destacar que para os produtos baseados em ciência exportados, observou-se uma variação bastante pequena entre a grande maioria dos países (com exceção para o caso da Suíça). Ou seja, apesar de estar entre aqueles com menores índices de sofisticação das exportações, nota-se que os preços destas representaram $91 \%$ do preço médio das exportações estadunidenses nos mesmos setores. Tal constatação parece trazer evidências de que, apesar das exportações chinesas nestes setores apresentarem menor relevância para o mercado mundial - expressa pela margem intensiva aqueles produtos aptos a se inserirem no mercado internacional apresentam qualidade similar à dos países líderes.

De acordo com a relação bilateral entre China e os países da amostra, mais uma vez observa-se que o nível de preços dos produtos exportados varia de maneira insignificante segundo os destinos (vide anexo 1). E, novamente, países (Hong Kong, índia, Tailândia e Coréia do Sul) constituintes da fábrica asiática são aqueles nos quais as exportações chinesas apresentam maiores margens intensivas. Entretanto, mesmo para estes países, a relevância relativa chinesa é menor quando comparada a importância de suas exportações nos blocos de setores diferenciados e intensivos em escala.

Por fim, no que se refere aos produtos intensivos em escala, a primeira constatação é que entre 2001 e 2017 a participação das exportações chinesas expressas pela margem intensiva cresceu cerca de $80 \%$ no período (vide anexo1). Tal fato permitiu que a China superasse países como Alemanha, EUA e Japão, na posição de país com maior margem intensiva em setores que envolvem produtos como químicos, metalúrgicos, equipamentos de transporte, entre outros. Entretanto, o aumento da margem intensiva não foi acompanhado pelo incremento da qualidade das exportações.

Adicionalmente, em perspectiva comparada nos produtos intensivos em escala observa-se um aumento da distância entre o nível de sofisticação das exportações chinesas e aquelas dos principais países analisados, o que fez com que a China ainda se caracterizasse em 2017 como o país com menor nível de preços. Com relação à Alemanha, tais preços representavam 83\% em 2001 e 77\% em 2017. Já com relação ao país com maior nível de sofisticação em 2017 - Suíça - a relação decresceu de 63\% para 55\%. A evolução de tais 
indicadores faz com que, grosso modo, estes setores se situem em uma situação intermediária entre os movimentos observados nos setores diferenciados e aqueles intensivos em ciência.

Por sua vez, ao se analisar a integração bilateral, como pode ser vista no anexo 1, os padrões verificados nos setores diferenciados e baseados em ciência parecem se reproduzir: (i) há uma tendência razoavelmente generalizada de aumento da margem intensiva, (ii) observa-se uma variação muito pequena dos índices de sofisticação de exportação segundo países - ainda que, invariavelmente, alguns países asiáticos como Hong Kong, Japão e Cingapura importem produtos com maiores preços relativos, e (iii) as maiores margens intensivas são observadas nos países que constituem a fábrica asiática .

Em síntese, conclui-se que a análise dos indicadores de margem intensiva e de qualidade para os setores diferenciados, baseados em ciência e intensivos em escala trazem elementos que corroboram parcialmente o processo virtuoso de transformação produtiva e tecnológica chinesa no que diz respeito à inserção internacional. Tal processo, em termos gerais, é caracterizado (i) pelo aumento generalizado da relevância das exportações em terceiros mercados em paralelo (ii) a uma tendência de incremento da sofisticação e da qualidade dessas, (iii) movimentos esses que ocorrem com ênfase ainda maior nos países constituintes da fábrica asiática. Não obstante, também se verifica que (iv) invariavelmente, as margens de qualidade das exportações - mensuradas pelo índice de preços - encontram-se numa posição inferior quando comparado às principais economias em termos de desenvolvimento produtivo e tecnológico.

\section{Conclusões}

Este trabalho buscou analisar o processo de transformação da estrutura produtiva chinesa sob a perspectiva do comércio internacional. Para isto, apresentaram-se as principais reformas engendradas pelo país a fim de possibilitar uma inserção internacional associada à diversificação produtiva e tecnológica. Ademais, avaliou-se a qualidade da inserção internacional chinesa pela perspectiva dos preços dos bens exportados, relacionando a qualidade das exportações ao índice de preço e o volume exportado à margem intensiva.

Concatenada a perspectiva de transformação estrutural e de inserção internacional diferenciada, a China apresentou evidências de ter uma cesta exportadora próxima à de países desenvolvidos, porém ainda fortemente presente em fluxos de baixa qualidade. Assim, para verificar a relação entre volume exportado e a sofisticação das exportações, este trabalho utilizou-se do método de Hummels e Klenow (2005) adaptado para categorizar os setores industriais para tipos de tecnologia (baseada em ciência, intensiva em escala e diferenciada).

Como resultado, encontrou-se que, para os setores diferenciados, a China ainda permanece entre os países com menor qualidade, em 2017, ainda que tenha superado Japão, Alemanha e EUA na margem intensiva (volume). Com relação aos produtos intensivos em escala, nota-se um aumento da participação das exportações chinesas não acompanhadas pelo incremento da qualidade das exportações. Por fim, nos setores baseados em ciência houve crescimento da margem intensiva, mas as exportações nesta tecnologia são as menores na economia mundial, quando comparadas as demais. Com relação à qualidade das exportações nessa tecnologia, a China ainda se concentra entre os três países com menores índices de preços na amostra. Com isso, conclui-se que apesar do aumento da relevância das exportações em terceiros mercados e incrementos na sofisticação e qualidade dessas, o índice de qualidade das exportações encontra-se numa posição inferior quando comparado às principais economias em termos de desenvolvimento produtivo e tecnológico. 
Logo, considerando a hipótese do trabalho, tem-se que apesar da transformação na estrutura produtiva e da reorientação da pauta exportadora chinesa para produtos de maior conteúdo tecnológico, reforçados pelos dados do valor adicionado manufatureiro e exportações de alta intensidade tecnológica e pelos trabalhos de Schott (2008), Hiratuka e Cunha (2011) e Gomes e Silva (2020), o efeito desses fatores sobre o preço, isto é, a qualidade das exportações, não é uma consequência necessária, que pode ser compreendido pela idiossincrasia da sofisticação chinesa conforme destacou Rodrik (2006). A título de ilustração dos resultados, é possível, por exemplo, analisar o aumento do volume de valor adicionado manufatureiro na tecnologia intensiva em escala, aumento da margem intensiva (volume exportado) no comércio mundial e em todas as relações bilaterais e uma variação pouco expressiva no indicador de qualidade (índice de preço) no comércio mundial e bilateral.Com isso, pode-se concluir que o trabalho reforça os resultados de Schott (2008), que apresentou maior similaridade da cesta de exportações chinesa em relação aos países da OCDE sem correspondência no aumento dos preços.

\section{Referências}

Acioly, L. (2005). China: Uma Inserção Diferenciada. Revista de Economia Política Internacional: Uma Análise Estratégica, S.l.(7). Disponível em: 〈http://goo.gl/j3zMdr〉.

Aiginger, K. (2001). Measuring the Intensity of Quality Competition in Industries. WIFO. Quarterly. Disponível em: 〈http://goo.gl/B9KgJy>.

Archibugi, D., \& Michie, J. (1998). Technical Change, Growth and Trade: new departures in institutional economics. Journal of Economic Surveys, 12(3), 313-332.

Borbély, D. (2005). EU Export Specialization Patterns in Selected Accession and Cohesion Countries: Tough Competition on the EU15 Market. Papeles del Este,9.

Cassiolato, J. E. (2013). As Políticas de Ciência, Tecnologia e Inovação na China. Repositório do Conhecimento do IPEA. Boletim de Economia e Política Internacional.

Cassiolato, J. E., \& Podcameni, M. G. B. (2015). As Políticas de Ciência, Tecnologia e Inovação na China. In: China em Transformação: Dimensões Econômicas e Geopolíticas do Desenvolvimento, IPEA.

Cimoli, M., Dosi, G., Nelson. R. R., \& Stiglitz J. (2007). Instituições e Políticas Moldando o Desenvolvimento Industrial: Uma Nota Introdutória. Revista Brasileira de Inovação, Rio de Janeiro, 6(1).

China Statistical Yearbook. (2019). Price Index. Disponível em:<http://www.stats.gov.cn/tjsj/ndsj/2019/indexeh.htm>.

CROTTY, J. The Effects of Increased Product Market Competition and Changes in Financial Markets on the Performance of Nonfinancial Corporations in the Neoliberal Era. University of Massachusetts, Amherst. October 11, 2002. 
European Chamber. (2017). China Manufacturing 2025: Putting Industrial Policy ahead of Market Forces. Disponível em: $<$ http://docs.dpaq.de/12007european_chamber_cm2025-en.pdf>.

Fontagné, L., Gaulier, G., \& Zignago, S. (2008). Specialization across Varieties and North-South Competition. Economic Policy, 23(53), 52-91.

Gao, Y., Whalley, J., \& Ren, Y. (2014). Decomposing China's Export Growth into Extensive Margin, Export Quality and Quantity Effects. China Economic Review, 29, 19-26.

Gomes, G. N. (2017). Catching up ou Falling Behind? As Transformações da Estrutura Produtiva Brasileira em comparação a Indústria Internacional entre o período de 1995 a 2014. Dissertação de Mestrado do Programa de Pós-Graduação em Economia da Universidade Federal de São Carlos (UFSCar).

Gomes, G. N., \& Silva, R. O. (2020). Diversificação e Qualidade das Exportações de Manufaturados no Comércio Mundial. Revista de Economia Mackenzie, 17(1), 61-91.

Hallak, J. C. (2006). Product Quality and the Direction of tTrade. Journal of International Economics, 68(1), 238-265.

Hausmann, R., Hwang, J., \& Rodrik, D. (2007). What you Export Matters. Journal of Economic Growth, 12(1), 1-25.

Hiratuka, C., \&Cunha, S. F. (2011). Qualidade e Diferenciação das Exportações Brasileiras e Chinesas: Evolução Recente no Mercado Mundial e na Aladi. IPEA. Brasília. Disponível em: 〈http://goo.gl/iqjvP7>.

Hummels, D., \& Klenow, P. J. (2005). The Variety and Quality of a Nation's Exports. American Economic Review, 95(3), 704-723.

Kaldor, N. (1966). Causes for the Slow Rate of Growth in the United Kingdom. Cambridge: Cambridge University Press.

Lardy, N. (2004). China: The Great New Economic Challenge? Institute for International Economics, Washington, DC.

Lazonick, W., \& Sullivan, M. (2000). Maximizing Shareholder Value: A New Ideology for Corporate Governance. Economy and Society, 29(1),13-35.

Masiero, G., \& Coelho, D. B. (2014). A Política Industrial Chinesa como Determinante de sua Estratégia Going Global. Revista de Economia Política, 34((134), 139157.

Milaré, L. F. L.(2011). O Processo de Industrialização Chinesa: Uma Visão Sistêmica. Dissertação de Mestrado da Universidade Federal de São Carlos (UFSCar), 176 f.

Nassif, A. (2008). Há Evidências de Desindustrialização no Brasil? Brazilian Journal of Political Economy, 28((109), 72-96. 
Nonnemberg, M. J. B. (2014). Participação em Cadeias Globais de Valor e Desenvolvimento Econômico. Boletim de Economia e Política Internacional. BEP, 17.

Nonnemberg, M. J. B., \& Mesentier, A. (2012). Is China only Assembling Parts and Components? The Recent Spurt in High Tech Industry. Revista Economia Contemporânea, Rio de Janeiro/RJ, 16(2),287-315.

OECD. (1987). Structural Adjustment and Economic Performance. Paris: Organization for Economic Cooperation and Development.

OECD. (ANO???) Trade in Value Added. Disponível em:< http://stats.oecd.org/index.aspx?r=59951\&erroCode=403\&lastaction=login_submit\#>.

Pavitt, K. (1984). Sectoral Patterns of Technical Change: Towards a Taxonomy and a Theory. Research Policy, 13, 343-373.

Pinto, E. C. (2011). O Eixo Sino-Americano e as Transformações do Sistema Mundial: Tensões e Complementaridades Comerciais, Produtivas e Financeiras. In: Leão, R. P. F., Pinto, E. C., \& Acioly, L. (Org.). A China na Nova Configuração Global: Impactos Políticos e Econômicos. Brasília: IPEA, Cap 2. Disponível em: 〈http://goo.gl/mhRHB6>.

Rodrik, D. (2006). What's so Special about China's Exports? NBER, 1947, 1-27. Disponível: <http://goo.gl/MZic55>.

Sarti, F., \& Hiratuka, C. (2010). Indústria Mundial: Mudanças e Tendências Recentes. Texto para Discussão. IE/UNICAMP, 186.

Schott, P. (2004). Across-Product Versus Within-Product Specialization in International Trade. The Quarterly Journal of Economics, 119(2), 646-677.

Schott, P. (2008). The Relative Sophistication of Chinese Exports. Yale School of Management. Disponível em: 〈http://goo.gl/v1B2XI>.

Trademap. (2017). Trade Statistics for International Business Development. Disponível em: < http://www.trademap.org/Index.aspx>.

United Nations Industrial Development Organization. (2020). Valor Adicionado. INDSTAT 2 2020, ISIC Revision 3. Disponível em: <https://stat.unido.org/database/INDSTAT\%202\%202020,\%20ISIC\%20Revision\%203>.

World Bank. Development Data. Vários Dados. Disponível em: $<$ http://databank.worldbank.org/data/views/reports/tableview.aspx >. 


\section{ANEXOS}

Anexo 1: Margem intensiva e índice de preços do comércio bilateral chinês e de países selecionados nos setores intensivos em escala, baseados em ciência e diferenciados - 2001 e $2017^{16}$

\begin{tabular}{|c|c|c|c|c|c|c|c|c|c|c|c|c|}
\hline \multirow{3}{*}{ Países } & \multicolumn{6}{|c|}{ Margem Intensiva } & \multicolumn{6}{|c|}{ Índice de Preços (Margem de Qualidade) } \\
\hline & \multicolumn{2}{|c|}{$\begin{array}{l}\text { Intensivos em } \\
\text { Escala }\end{array}$} & \multicolumn{2}{|c|}{$\begin{array}{l}\text { Baseados em } \\
\text { Ciência }\end{array}$} & \multicolumn{2}{|c|}{ Diferenciados } & \multicolumn{2}{|c|}{$\begin{array}{l}\text { Intensivos em } \\
\text { Escala }\end{array}$} & \multicolumn{2}{|c|}{$\begin{array}{c}\text { Baseados em } \\
\text { Ciência }\end{array}$} & \multicolumn{2}{|c|}{ Diferenciados } \\
\hline & 2001 & 2017 & 2001 & 2017 & 2001 & 2017 & 2001 & 2017 & 2001 & 2017 & 2001 & 2017 \\
\hline Austrália & 0,088 & 0,291 & 0,021 & 0,073 & 0,050 & 0,287 & 0,99991 & 0,99995 & 1,00096 & 1,00016 & 0,99972 & 0,99979 \\
\hline França & 0,016 & 0,046 & 0,007 & 0,037 & 0,021 & 0,097 & 0,99993 & 0,99999 & 0,99983 & 1,00022 & 0,99952 & 0,99985 \\
\hline Alemanha & 0,031 & 0,058 & 0,007 & 0,039 & 0,041 & 0,129 & 0,99997 & 0,99997 & 0,99950 & 0,99990 & 0,99953 & 0,99977 \\
\hline Hong Kong & 0,306 & 0,372 & 0,274 & 0,393 & 0,312 & 0,555 & 0,99997 & 1,00002 & 0,99951 & 0,99983 & 0,99966 & 1,00008 \\
\hline Japão & 0,162 & 0,334 & 0,064 & 0,051 & 0,186 & 0,408 & 0,99999 & 0,99999 & 0,99989 & 0,99986 & 0,99985 & 0,99990 \\
\hline Coreia do Sul & 0,147 & 0,321 & 0,013 & 0,079 & 0,098 & 0,264 & 0,99995 & 0,99995 & 0,99946 & 1,00010 & 0,99963 & 0,99979 \\
\hline Holanda & 0,057 & 0,131 & 0,003 & 0,027 & 0,054 & 0,195 & 0,99988 & 0,99992 & 0,99921 & 0,99944 & 0,99955 & 0,99978 \\
\hline Polônia & 0,021 & 0,062 & 0,007 & 0,018 & 0,025 & 0,145 & 0,99983 & 0,99991 & 0,99855 & 0,99974 & 0,99915 & 0,99963 \\
\hline Rússia & 0,046 & 0,211 & 0,017 & 0,013 & 0,032 & 0,276 & 0,99988 & 0,99990 & 0,99726 & 0,99959 & 0,99978 & 0,99972 \\
\hline Índia & 0,175 & 0,344 & 0,029 & 0,149 & 0,063 & 0,351 & 0,99991 & 0,99991 & 0,99895 & 0,99974 & 0,99949 & 0,99971 \\
\hline Singapura & 0,086 & 0,206 & 0,032 & 0,041 & 0,077 & 0,204 & 0,99996 & 1,00002 & 0,99948 & 0,99988 & 0,99966 & 0,99993 \\
\hline Vietnã & 0,283 & 0,396 & 0,013 & 0,072 & 0,115 & 0,365 & 0,99977 & 0,99993 & 0,99866 & 0,99947 & 0,99980 & 0,99985 \\
\hline Espanha & 0,024 & 0,089 & 0,002 & 0,014 & 0,021 & 0,115 & 0,99984 & 0,99993 & 0,99968 & 1,00008 & 0,99940 & 0,99974 \\
\hline Suíça & 0,014 & 0,031 & 0,004 & 0,022 & 0,008 & 0,040 & 1,00038 & 1,00020 & 0,99827 & 1,00237 & 0,99937 & 1,00009 \\
\hline Tailândia & 0,066 & 0,310 & 0,009 & 0,091 & 0,059 & 0,278 & 0,99993 & 0,99991 & 0,99936 & 0,99962 & 0,99981 & 0,99979 \\
\hline Turquia & 0,037 & 0,113 & 0,002 & 0,018 & 0,040 & 0,195 & 0,99975 & 0,99989 & 0,99820 & 0,99942 & 0,99900 & 0,99971 \\
\hline Reino Unido & 0,038 & 0,106 & 0,002 & 0,032 & 0,038 & 0,145 & 0,99993 & 0,99996 & 0,99950 & 0,99973 & 0,99949 & 0,99976 \\
\hline EUA & 0,080 & 0,206 & 0,023 & 0,071 & 0,077 & 0,215 & 0,99993 & 0,99995 & 0,99967 & 0,99963 & 0,99967 & 0,99978 \\
\hline
\end{tabular}

\footnotetext{
${ }^{16}$ A Malásia não estava presente no ano de 2017. A Bélgica, Canadá, Itália, México, Emirados Árabes não estavam presentes em 2001 de forma que os países foram excluídos da apresentação.
} 